\title{
Middle and Elementary School Students' Changes in Self-Determined Motivation in a Basketball Unit Taught using the Tactical Games Model
}

\author{
by \\ Stephen Harvey ${ }^{1}$, Alexander Gil-Arias², Megan Lorraine Smith ${ }^{3}$, \\ Lindsey Rachel Smith ${ }^{4}$
}

\begin{abstract}
Studies examining student motivation levels suggest that this is a significant factor in students' engagement in physical education and may be positively affected when teachers employ alternative pedagogical models such as game-centered approaches (GCAs). The aim of this study was to investigate changes in self-determined motivation of students as they participated in a GCA-basketball unit taught using the Tactical Games Model (TGM). Participants were 173 students (84 girls), 79 middle school (45 girls) and 94 (39 girls) elementary school students from four seventh and five fourth/fifth grade co-educational classes. Two teachers taught 32 (middle) and 33 (elementary) level one TGM basketball lessons. Need satisfaction and self-determined motivation data were collected using a previously validated instrument, while lesson context and teacher behavior data were recorded using systematic observation instruments. Repeated measures MANOVAs were employed to examine pre-posttest differences. Results revealed a significant main effect for time in need satisfaction for both middle (relatedness increased) and elementary school students (autonomy decreased) and a significant main effect in self-determined motivation for middle school students only (introjected regulation, external regulation, and amotivation all increased). Approximately $48 \% / 42 \%$ (middlelelementary) of lesson time was game play, $22 \% / 22 \%$ skill practice, $17 \% / 17 \%$ management, and $13 \% / 19 \%$ knowledge. The primary teacher behaviors used were instruction, management, specific observation, corrective feedback and modelling. Results indicate that it is important for future research to pay greater attention to the contextual factors associated with the application of the TGM, such as the students' previous exposure to TGM lessons, and the teachers' training and experience in utilizing the TGM. Indeed, results of the present study demonstrate that a longer-term commitment to the TGM is necessary to reduce controlling teacher behaviors, which will lead to positive changes in students' need satisfaction and self-determined motivation. Future research is therefore needed to embrace this challenge to provide an increased evidence-base for GCAs such as the TGM.
\end{abstract}

Key words: pedagogical models, physical education, motivation, basic psychological needs..

\section{Introduction}

In physical education, teaching has traditionally been undertaken using a direct instruction pedagogical model. In this model, the teacher is directly responsible for all decisions, which includes the establishment of objectives, lesson management, task presentations, teaching strategies, students' responsibilities, etc. (Metzler, 2011). This 'one-size-fits-all' model has recently been referred to by Kirk (2010) as physicaleducation-as-sport-techniques where the main aim is to develop 'technical proficiency' (Light et al., 2015; Oslin and Mitchell, 2006) due to its

1 - Ohio University, USA.

2 - Rey Juan Carlos University, Spain.

3 - West Virginia University, USA.

4 - University of Bedfordshire, UK. 
emphasis on 'skills first' orientation where skills are learned 'before the introduction of rules and game play' (Light and Fawns, 2003). Bunker and Thorpe (1982) critiqued the direct instruction model of games teaching, arguing that most students obtained little game understanding during physical education lessons taught using this model and, as a result, possessed inflexible techniques and poor decision-making skills (see Stoltz and Pill, 2014 for a further review).

As a way of expanding the focus of physical education and its goals and purposes beyond a 'training' model, Metzler (2011) offered seven alternative pedagogical models that are used within the curriculum outside direct instruction. One such a model, the Tactical Games Model (TGM) is an Americanized derivative of the Teaching Games for Understanding (TGfU) approach (Bunker and Thorpe, 1982). In contrast to the direct instruction model, game-centered approaches (GCAs) such as TGfU and TGM prioritize learning in the cognitive domain. For example, students learn the tactical aspects of the game first by playing a developmentally appropriate small-sided and/or modified/conditioned version of the game (Harvey and Jarrett, 2014). In this sense, the what (i.e. decision making) therefore comes before the how (i.e. skill execution) in GCAs such as the TGM refuting the notion that quality game play cannot emerge until the core techniques are mastered a priori, instead it offers a way of linking techniques and tactics with the aim of promoting skillful and intelligent performance (Mitchell et al., 2006; Oslin and Mitchell, 2006). However, although the cognitive domain is prioritized through the teachers' skilful task design, technical skills are simultaneously developed alongside tactics in contextualized situations using the pedagogical principles of modification (representation and exaggeration) and tactical complexity (Werner et al., 1996). Scholars have argued that through this interaction between the tactical and technical dimensions of play, student motivation in physical education is increased (Jones et al., 2010, Mandigo et al., 2008; Ntoumanis and Standage, 2009).

Studies examining student motivation levels suggest that this is a significant factor in students' propensity to engage in physical education (Gillet et al., 2012; Jones et al., 2010;
Taylor and Ntoumanis, 2007; Standage et al., 2005, Wallhead and Ntoumanis, 2004). One theory that can help explain student motivational processes in physical education contexts is SelfDetermination Theory (SDT; Deci and Ryan, 2000). SDT is based upon three innate psychological needs: competence (i.e. desire to interact efficiently with the environment and situation), autonomy (i.e. desire to commit to an activity due to one's own choice) and relatedness (i.e. desire to feel part of the group) (Ryan and Deci, 2000). If these innate needs are satisfied, the individual becomes more autonomously motivated and this, in turn, gives rise to high quality motivation (Ryan and Deci, 2000). Autonomous motivation (i.e. self-regulated behavior) falls into two categories: intrinsic and identified regulation (McLachlan and Hagger, 2010). Intrinsic motivation gives rise to higher quality motivation and this allows the individual to feel more stimulated and motivated by physical education, which has been shown to lead to increases in physical activity (PA) during physical education lessons (Lonsdale et al., 2009; Perlman, 2012; Wallhead et al., 2010). In addition, Standage et al. (2005) demonstrated that when an environment high in self-determination was created, students' intrinsic motivation was enhanced and this predicted participation and effort during physical education lessons.

Narrative systematic reviews of the field of TGM research (Harvey and Jarrett, 2014; Miller, 2015; Oslin and Mitchell, 2006; Stolz and Pill, 2014) claim that due to the interaction between the tactical and technical dimensions of play within the TGM, students taught via TGMs are more motivated in physical education lessons. For example, Mandigo et al. (2008) investigated differences between 759 boys and girls from 37 different co-educational upper elementary-aged classes on different SDT constructs (i.e. competence, relatedness, autonomy-supportive and enjoyment) after they were taught via a oneoff 'autonomy supportive' games lesson (similar to TGM) in one of four games categories. Results obtained from their 22-item questionnaire drawing on SDT's theoretical model as well as qualitative comments from students, found significant sex differences with girls reporting higher optimal challenge, perceived autonomysupport and enjoyment, whereas boys reported 
higher levels of perceived competence.

Recently, Moy et al. (2015) examined intrinsic motivation of 54 physical education teacher education students during their participation in two track and field lessons: one focused on direct instruction and one used the constraints-led approach, which has been argued to have similar features to GCAs such as TGM. Responses to motivational measures of basic psychological needs and indices of intrinsic motivation, effort and enjoyment questionnaires showed significantly higher levels of the preservice teachers' self-determination and intrinsic motivation during the constraints-led approach hurdle lesson when compared to the direct instruction lesson, irrespective of the order in which these students were delivered the lesson. This led Moy et al. (2015) to conclude that the constraints-led approach could facilitate developments of physical education students' intrinsically motivated behaviors. One major limitation in the two studies of Mandigo et al. (2008) and Moy et al. (2015) was that the students and/or pre-service teachers participated in only one lesson. Indeed, there have been few follow-up studies especially over prolonged unit lengths and in different games/categories of games.

Two studies that have been conducted over prolonged unit lengths were undertaken by Jones et al. (2010) and Smith et al. (2015). Jones et al. (2010) investigated changes in the six subscales of the Intrinsic Motivation Inventory (IMI) (perceptions of interest/enjoyment, sport competence, effort/importance, choice, pressure/tension and usefulness) to ascertain differences between 11-14-year-old groups taught using direct instruction and a TGfU approach in single-sex groupings over the course of a six-week basketball unit. They found significant differences on all six subscales at the conclusion of the unit, also noting significant gender and interaction effects where 'girls perceived TGfU related activities to fulfill individual needs and provide satisfaction more than boys' (p. 61). However, in a more recent study, Smith et al. (2015) investigated changes in boys $(n=42)$ and girls' $(n=30)$ selfdetermined motivation during two back-to-back TGM-focused invasion game units. These authors did not find any significant differences in selfdetermined motivation for boys or girls in TGMfocused groups when compared to direct instruction groups.

Not only have some of these previous GCA-focused studies been conducted over single one-shot lessons, studies that have examined student motivation over prolonged time periods have tended to ignore motivational climate variables such as lesson context and/or teacher behaviors. This is surprising given the importance of students' perceptions of teachers' autonomy support or controlling behavior within physical education. Ennis (1999) notes that pedagogical models focused on hard masculinized pedagogy with "an underlying emphasis on competition, winning and dominance" (p. 43) such as direct instruction have tended to marginalize some learners, particularly girls, and affect their engagement in, and motivation for, physical education. Ennis (1999) argues that alternative pedagogical models, particularly, second generation models such as TGM, which are underpinned by constructivist learning theory (Kirk and MacDonald, 1998), "help the teacher to change and sustain a more equitable focus" (p. 43), challenging the "taken for granted curricular structures" (p. 43) and change the role of the teacher from "micro-manager" to "facilitator" (p. 43). For example, the teacher's use of GCAs such as the TGM provides an autonomous environment compared to direct instruction approaches where the majority of decisions are made by the instructor (Goudas et al., 1995; Morgan et al., 2005). Moreover, domain interactions (Metzler, 2011) such as the teacher emphasizing the cognitive and tactical components of play and, importantly, using 'softer' pedagogies (Light and Kentel, 2010) such as questioning to support problem-solving via discussion, debate and dialogue during GCAfocused lessons allows the teacher time to listen, give praise and respond to the answers encouraging more autonomous (intrinsic) motivation within the lesson (Reeve and Jang, 2006).

Harvey et al. (2016) recently used the lesson context variables from the Systematic Observation of Fitness Instruction Time instrument (SOFIT; McKenzie, 2012) and teacher behaviors from the West Virginia Teaching Evaluation Instrument (WVUTES; Hawkins and Wiegand, 1989). While these authors did not specifically examine student motivation, Harvey 
and colleagues (2016) suggested that the utilization of these instruments could "enable teachers to develop pedagogical alignments within student-centered physical education models" (p. 425). Indeed, the notion of stepping back and being a 'problem setter' rather than 'problem solver' has been noted as a key 'dilemma' when teachers use a GCA (Harvey et al., 2015). The systematic observation of teachers' behaviors enables the examination of this key teaching tactic. Additional research in physical education by De Meyer et al. (2014) found that as the frequency of controlling teacher behaviors increased, students reported their teachers as more controlling which in turn made students feel more pressured to engage in physical education. Moreover, there was an indirect relationship between controlling teacher behavior and amotivation.

In the context of this previous research, the purpose of the current study was to investigate potential changes in middle and elementary school students' perceptions of need satisfaction and self-determined motivation over the duration of a TGM-focused basketball unit. It was hypothesized that given the differences in domain interaction and lesson structure inherent in the TGM, students would increase their perceptions of need satisfaction and the quality of their motivation due to their experiences participating in TGM-focused lessons.

\section{Methods}

\section{Participants}

Participants were 173 students (84 girls), 79 middle school (45 girls) and 94 (39 girls) elementary school students from four seventh and five fourth/fifth grade co-educational classes at two schools in the Mid-Western United States, respectively. These schools were chosen because their teachers and students had no previous exposure to GCAs such as the TGM, either in their present schools, or in previous grade levels. In line with our study aims, a quasi-experimental pretest - posttest design was utilized.

Ethical approval for this study was granted by an Institutional Review Board (IRB) for the protection of human subjects at a large MidWestern United States University. All participants were treated in agreement with the ethical guidelines of the American Psychological
Association with respect to participant assent, parent/guardian consent, confidentiality and anonymity. Permission was also gained from the County School Board, school principals and the resident physical education teachers who signed an informed consent form.

There were two physical education teachers in this study, one middle school teacher and one elementary school teacher, both male. Both teachers had over 20 years of teaching experience. Both had or were currently coaching interscholastic basketball teams within the same school district where they taught PE, but not within the same school they taught at. As the teachers had no previous experience teaching using the TGM, the use of basketball therefore gave the opportunity to ease the transition of the teachers to the TGM (Griffin, 1996).

Settings

TGM lessons were taught in an indoor gymnasium of $40 \times 30$ yards and had six baskets available at both schools. Lessons covered were a replication of the level one TGM basketball lessons from the Teaching sports concepts and skills: A tactical games approach text (Mitchell et al., 2006). The middle school students had daily PE and lesson periods were between 43-47 minutes' bell to bell, which included dressing out time. In total, the middle school teacher taught a total of 32 lessons (four per day) during the month of November. Instead, the elementary school students only had one PE lesson per week and lesson periods were 40 minutes' bell to bell, which included the teacher needing to collect classes from their classroom and bring them to the gym. The elementary teacher taught the TGM lesson to each class once a week from January to March. Three classes received seven TGM sessions to get through the Level one TGM basketball content since they had multiple delayed lessons, whereas two classes did not and, thus, received six lessons. The elementary teacher therefore delivered a total of 33 TGM lessons.

For observed sessions, actual lesson instructional time averaged Mlength $=34 \mathrm{~min} 28 \mathrm{~s}$ and Mlength $=29 \min 58 \mathrm{~s}$ for the middle school and elementary schools, respectively. Lesson length at the elementary school was slightly shorter to the middle school because of slightly shorter class periods, but also because some lessons were shortened due to assembly (2 lessons) and 2-hour 
delays on days where there was inclement (wintery) weather where lessons were reduced by 10 minutes (5 lessons).

\section{Pre-Study Training of Teachers}

Teachers were supported in learning about and using the TGM via the first author. Initially, the first author met with the two teachers individually and overviewed the tenets of the TGM, concluding this meeting by asking whether they would be able to participate in the study. After this initial meeting, the first author provided the two teachers with copies of the first three chapters of Mitchell et al. (2006), and chapter 14 from Instructional Models in Physical Education (Metzler, 2011). They were additionally provided with a copy of chapter 5 from Mitchell et al. which outlined the lesson content for basketball. Once the teachers had read this material, the first author conducted a second individual meeting with each of the teachers to discuss the content covered in chapter 5 (Mitchell et al., 2006) and review model benchmarks from chapter 14 (Metzler, 2011), and address any questions and/or concerns.

\section{TGM Lesson Delivery}

Students were arranged into mixed ability teams of three by each of the two teachers using their previous knowledge of the students. Before each lesson the first author met both teachers individually and reviewed lesson content, which included the three lesson sections (game-skillgame) and transitions between the three, as well as the teachers' deductive questions from the Mitchell et al. (2006) lesson plans (e.g. 'When you receive the ball, what are your three options?'). The first author also provided the teachers with suggestions on how games or skill drills could be simplified to make games more developmentally appropriate (e.g., both hands behind back defense) but still meet model benchmarks (Metzler, 2011). In lesson 5 (tactical problem of attacking the basket) the teacher started with a 3 vs. 3 game with the condition of no dribbling unless to drive to the basket. The teacher would stop this initial game, gather the class around one basket and asked deductive questions in line with those outlined by Mitchell et al. (2006) to aid learning. The teacher then demonstrated with students how to set up the skill drill practice. This practice involved three players. One player would defend with arms behind their back (an additional modification to ease the initial task complexity), a second player, on receipt of a pass from a third player, would ball fake, juke or jab step, and drive to basket, making a jump stop to shoot the ball. The final part of the lesson involved the same 3 vs. 3 conditioned game, this time, with the additional condition that each team must dribble and drive to basket as often as possible.

\section{Post-lesson Teacher Feedback}

Researcher/teacher post-lesson discussion occurred between taught sessions so that the teacher could ensure that they continued to meet model benchmarks controlling for possible teacher drift over the course of the study. For example, the first author overviewed the gameskill-game lesson format, the utilization of deductive questions, game modifications and skill drills, as well as adherence to model benchmarks (Metzler, 2011).

\section{Instruments and Data Generation}

The first author and at least two other trained observers were present at each PE lesson to conduct lesson context and teacher behavior analyses and assess the two teacher's fidelity to model benchmarks.

Model benchmarks.

The TGM lessons were assessed using benchmarks to ensure that lessons were implemented correctly and not detrimental to learning outcomes (Metzler, 2011). While benchmarks offer key criteria to determine if the teacher is 'doing the model' it has been suggested that not all benchmarks need to be met when using curriculum models (Hastie and Casey, 2014). For this study, we followed the lead of Gurvitch et al. (2008) in selecting four key 'nonnegotiable' teacher benchmarks, which included: teacher uses tactical problems as the organizing center for the learning tasks, teacher begins each lesson with a game form to assess students' knowledge, teacher uses deductive questions to get students to solve tactical problems, teacher uses high rates of guides and feedback during situated learning tasks. 'Non-negotiable' student benchmarks utilized for model fidelity were: students are given time to think about deductive questions regarding the technical problem, students understand how to set up situated learning tasks, students are making situated tactical decisions, game modifications developmentally appropriate (for a complete list 
of model benchmarks, see Metzler, 2011). The first author as well as one additional observer were trained to code model benchmarks.

Need satisfaction and motivation questionnaire.

The constructs included in need satisfaction and self-determined motivation were assessed pre- and post-intervention using standard protocols based on components of a previously validated questionnaire developed by Standage et al. (2005). Standage et al. (2005) developed this questionnaire to measure all aspects of SDT within a sport and physical education context using a Likert scale ranging from 1 = strongly disagree to $7=$ strongly agree. The questionnaire measured need satisfaction which was comprised of the three innate needs of autonomy, competence and relatedness alongside questions relating to the continuum of SDT (levels of intrinsic motivation), which had been previously shown to be indices of the function of autonomous regulation (Standage et al., 2005).

More specifically, need satisfaction was assessed by measuring three variables: autonomy -6 items (e.g. I have some choice of what I want to do) with one reverse-scored item 'I have to force myself to do the activities', competence -5 items (e.g. I think I am pretty good at PE), relatedness -6 items (e.g. with the other students in this PE class I feel supported). In terms of selfdetermined motivation, intrinsic motivation (e.g. I take part in this PE class because PE is exciting), identified regulation (e.g. I take part in this PE class because I want to learn sport skills), introjected regulation (e.g. I take part in this PE class because it bothers me when I don't), external regulation (e.g. I take part in this PE class because that's the rule) and amotivation (e.g. I take part in this PE class but I don't see why we have PE) were all assessed using four items. Previous research (Standage et al., 2005) with similar age participants to the current study had shown alpha coefficients ranging between 0.80 and 0.96 for these scales and can be considered internally reliable (Nunnally and Bernstein, 1994). An experienced researcher was present when the questionnaires were completed. The researcher overviewed how to complete the questionnaire and answered any questions that arose during the process. The questionnaires were completed in the absence of the physical education teacher. The questionnaires were given to all the participants in the same order and it took each participant between 15-20 minutes to complete the questionnaire.

Lesson context.

Lesson context was coded using definitions from the System for Observing Fitness Instruction Time (SOFIT) training manual (McKenzie, 2012). This involved coding the context of the lesson every 20 seconds (McKenzie, 2012). Lesson context codes were recorded as follows: $\mathrm{M}=$ general content (transition, break, management), $\mathrm{P}=$ knowledge content (physical fitness), $\mathrm{K}=$ general knowledge (rules, strategy, social behavior, technique), $\mathrm{F}=$ motor content fitness, $S=$ skill practice, and $G=$ game play. The first and third authors as well as two additional coders conducted all four parts of the SOFIT training included in the SOFIT manual and reached the acceptable levels of Inter Observer Agreement (IOA) with the gold standard within the lesson context section. When acceptable IOA levels (i.e. 80\%) were reached (McKenzie, 2012), observers undertook live coding on at least two occasions alongside the first author. On each occasion, acceptable IOA levels above $80 \%$ were reached (McKenzie, 2012).

Teacher behavior.

Teacher behavior data were collected using the West Virginia Teaching Evaluation System (WVUTES - the behavior categories of the WVUTES can be obtained from the first author; Hawkins and Wiegand, 1989). While initially developed for use with computer-based software, observers in this study employed the traditional paper and pencil method. The instrument includes the following 11 behaviors: general observation, specific observation, encouragement, positive feedback, negative (corrective) feedback, management, verbal instruction, modeling, physical guidance, non-task verbal and off-task.

To align with data collected via lesson context, teacher behaviors were also coded every 20 s using momentary time sampling. One behavior per interval was recorded. If two behaviors were evident in the same interval, the behavior with the higher ranking was recorded. For example, if both corrective feedback (ranked number 4) and general verbal instruction (ranked number 6) were noted within the same interval, general verbal instruction, i.e. the higher ranked variable, would be recorded. This instrument had 
previously been utilized in the context of the TGM literature (Harvey et al., 2016).

The first and third authors conducted the teacher behavior coding. Again, to align with data collected via the lesson context, teacher behavior coder training followed the same process as lesson context, and utilized the same videotaped records. Gold standard records of behaviors for each videotaped record from all four parts of the SOFIT training were constructed by the first author who reached acceptable IOA levels (McKenzie, 2012) with one of the originators of the WVUTES instrument (Potrac et al., 2002). The third author then coded the same videotaped records and reached acceptable IOA levels with the first author (McKenzie, 2012).

Observer reliability.

Due to the small number of items and choice of three alternatives, model benchmark IOA was set at $70 \%$ following guidelines from Osborne (2008). Prior to the study the first author and one additional coder observed videotaped records of three invasion game TGM lessons that were not part of the current study using the same 3-point scale as Gurvitch et al. (2008) of 'not at all', 'ok', and 'very well'. IOA levels for these three lessons were $100 \%, 88 \%$, and $100 \%$, thus averaging $96 \%$.

Model benchmark IOA during the study was conducted on $21.54 \%$ (14) of the 65 total sessions (randomly selected based on observer availability and training; McKenzie, 2012, and more than $10 \%$ of the total sample; Tabachnick and Fidell, 2014). IOA levels between the first author and the same previously trained pre-study coder averaged $78.33 \%$, with individual sessionby-session scores ranging from $62.50 \%$ (one session), $75 \%$ (nine sessions), $82.50 \%$ (three sessions) to $100 \%$ (one session).

Inter-observer reliability checks for lesson context data were completed for $21.54 \%$ (14) of the 65 lessons (randomly selected based on observer availability and training; McKenzie, 2012 and more than $10 \%$ of the total sample; Tabachnick and Fidell, 2014). Interval-by-interval IOA between the first author and the additional two observers averaged $97.25 \%$ (range 95-100\%), which exceeded minimum levels of agreement (McKenzie, 2012).

Inter-observer reliability checks for teacher behavior data were completed for $18.46 \%$
(12) of the 65 lessons (randomly selected based on observer availability and training; McKenzie, 2012). Interval-by-interval IOA between the first and third authors averaged $91.25 \%$ (range $85-$ $96 \%$ ), which exceeded minimum levels of agreement (McKenzie, 2012). In all instances, scores from the first author were used in subsequent data analyses (McKenzie, 2012).

\section{Data Analysis}

Model benchmarks.

Model benchmarks were recorded in 59 of the 65 lessons ( $91 \%$ of sessions). The percentage of benchmarks in each of the three categories of 'not at all', 'ok', and 'very well' across all study sessions was then calculated.

Need satisfaction and motivation questionnaire.

Data normality was examined through the Kolmogorov-Smirnov test, which led to the use of parametric statistics. Levene's tests were utilized to test for homogeneity between groups for follow-up analyses, none of which were significant. Cronbach's alpha levels were calculated for all scales within each data set (i.e. pre-and post for both elementary and middle school contexts) to assess the internal consistency of the measures. Cronbach's alpha levels greater than 0.70 were classed as acceptable (Nunnally and Bernstein, 1994) except for identified regulation in the elementary data set only. Results from the Cronbach's alpha test indicated that removing items from the identified regulation scale would not improve its reliability score over the critical level. However, due to the small number of items that make up the identified regulation, internal consistency can be accepted (Hair et al., 1998; Nunnally and Bernstein, 1994).

Two separate repeated measures MANOVAs were employed to assess any preposttest differences in needs satisfaction and selfdetermination constructs for each developmental level (i.e. middle and elementary schools), thus, four in total. A Bonferroni correction factor was used for these initial analyses, with selected alpha level set at $0.0125(0.05 / 4)$. If an overall multivariate effect was significant, the univariate ANOVAs were interpreted to examine which specific constructs contributed to the overall multivariate effect with Bonferroni corrections applied. Effect sizes were calculated using the partial eta-squared statistic $\left(\eta p^{2}\right)$. The alpha level was set at $p<0.05$, with a confidence interval for 
differences of 95\%. Version 24.0 of SPSS (SPSS Inc, Chicago, IL) was used for all statistical analyses.

Lesson context and teacher behavior.

Before data were analyzed, data from paper records were transferred to an electronic coding form constructed for the purposes of the current study. This ensured that calculations for each of the lesson context and teacher behavior categories were accurate. Descriptive lesson context and teacher behavior data (means and standard deviations) were calculated using percent of class time as the unit of measurement following standard protocols outlined by McKenzie (2012) for the SOFIT protocol and Hawkins and Wiegand (1989) for the WVUTES. For example, the percent of class intervals students spent in each lesson context/teacher behavior category were calculated for each lesson and a mean percentage score computed over the course of the 32 (middle) or 33 (elementary) observed lessons.

\section{Results}

\section{Model Benchmarks}

The middle school teacher met a preponderance of the eight model benchmarks (four teacher, four student) in each session taught. Ratings of 'not present' occurred on $3.13 \%$ and $0.78 \%$, 'ok' on $10.94 \%$ and $50 \%$ and 'very well' on $85.94 \%$ and $49.22 \%$ of the teacher and student items, respectively. The elementary teacher also met a preponderance of the eight model benchmarks. Ratings of 'not present' occurred on $1.85 \%$ and $1.85 \%$, 'ok' on $8.33 \%$ and $23.15 \%$ and 'very well' on $89.81 \%$ and $75 \%$ of the teacher and student items, respectively.

Need Satisfaction and Motivation Questionnaire

Main effects of MANOVA revealed a significant main effect for time in the needs satisfaction scales for both middle school (Wilks' Lambda $\left.=.81, F(3,73)=5.86, p=.001, \eta^{2}=.19\right)$ and elementary school (Wilks' Lambda $=.88, F(3$, $91)=4.11, p=.009, \eta_{p}^{2}=.12$ ). Follow-up univariate ANOVAs revealed that there was a significant increase in relatedness for the middle school group $\left(F(1,75)=9.88, p=.002, \eta^{2}=.12\right)$, while there was a significant reduction in autonomy for the elementary group $\left(F(1,93)=12.17, p=.001, \eta p^{2}\right.$ $=.12)$ (Table 3).

Table 1

Percent time spent in different lesson contexts in middle and elementary school TGM lessons

\begin{tabular}{ccccc}
\hline Lesson Context & $\begin{array}{c}\text { Middle School } \\
\mathrm{M}( \pm \mathrm{SD})\end{array}$ & $\begin{array}{c}\text { Total Intervals } \\
\mathrm{M}( \pm \mathrm{SD})\end{array}$ & $\begin{array}{c}\text { Elementary School } \\
\mathrm{M}( \pm \mathrm{SD})\end{array}$ & $\begin{array}{c}\text { Total Intervals } \\
\mathrm{M}( \pm \mathrm{SD})\end{array}$ \\
\hline Management & $16.59(4.84)$ & $533(5.93)$ & $17.50(4.89)$ & $515(4.32)$ \\
Knowledge & $13.11(6.46)$ & $438(7.10)$ & $18.64(5.73)$ & $567(6.43)$ \\
Skill Practice & $21.90(9.69)$ & $728(10.08)$ & $21.56(6.42)$ & $668(7.40)$ \\
Game & $48.39(15.09)$ & $1500(9.64)$ & $42.29(7.09)$ & $1277(9.91)$ \\
Total & 100 & 3199 & 100 & 3027 \\
\hline
\end{tabular}


Table 2

Percent time spent in different teacher behaviors in middle and elementary school TGM lessons

\begin{tabular}{lcccc}
\hline \multicolumn{1}{c}{ Teacher Behavior } & $\begin{array}{c}\text { Middle School } \\
\mathrm{M}( \pm \text { SD) }\end{array}$ & $\begin{array}{c}\text { Total Intervals } \\
\mathrm{M}( \pm \text { SD) }\end{array}$ & $\begin{array}{c}\text { Elementary School } \\
\mathrm{M}( \pm \text { SD })\end{array}$ & $\begin{array}{c}\text { Total Intervals } \\
\mathrm{M}( \pm \text { SD })\end{array}$ \\
\hline General observation & $5.54(3.63)$ & $180(3.94)$ & $7.75(3.82)$ & $180(5.93)$ \\
Encouragement & $0.87(1.11)$ & $27(1.06)$ & $0.21(0.40)$ & $27(7.10)$ \\
Positive feedback & $4.84(2.54)$ & $151(2.49)$ & $3.28(2.00)$ & $151(10.08)$ \\
Corrective feedback & $11.50(3.44)$ & $368(3.96)$ & $10.30(3.36)$ & $3689.64)$ \\
Management & $22.37(6.59)$ & $719(8.05)$ & $19.08(6.24)$ & $719(9.64)$ \\
Verbal instruction & $31.66(4.75)$ & $1012(6.43)$ & $31.41(6.46)$ & $1012(9.64)$ \\
Modelling & $6.66(4.61)$ & $220(5.04)$ & $9.25(3.61)$ & $220(9.64)$ \\
Physical guidance & $0.86(1.09)$ & $27(1.02)$ & $1.45(1.75)$ & $27(9.64)$ \\
Non-task verbal & $2.18(1.80)$ & $70(1.91)$ & $0.91(1.42)$ & $70(9.64)$ \\
Off-task & $2.78(2.95)$ & $84(2.31)$ & $5.24(5.65)$ & $84(9.64)$ \\
Specific observation & $10.74(3.92)$ & $341(4.21)$ & $11.43(4.11)$ & $341(9.64)$ \\
Total & 100 & 3199 & 100 & 3027 \\
\hline
\end{tabular}

Table 3

Students' need satisfaction (i.e., autonomy, relatedness and competence) in middle and elementary school TGM lessons

\begin{tabular}{|c|c|c|c|c|c|c|}
\hline Need Satisfaction & $\begin{array}{c}\text { Alpha } \\
\text { (pre/post) }\end{array}$ & $\begin{array}{c}\text { Pre } \\
(\mathrm{M} \pm \mathrm{SD})\end{array}$ & Post $(\mathrm{M} \pm \mathrm{SD})$ & 95\% CI [pre/post] & $\mathrm{F}$ & $p$ \\
\hline Autonomy MS & $0.77 / 0.76$ & $4.58(1.29)$ & $4.71(1.26)$ & [4.28-4.87/4.42-5.00] & 1.23 & 0.27 \\
\hline Autonomy ES & 0.78/0.77+ & $4.27(1.54)$ & $3.81(1.45)$ & [3.96-4.59/3.52-4.11] & 12.17 & $0.01^{* *}$ \\
\hline Competence MS & $0.85 / 0.78$ & $5.74(1.22)$ & $5.57(1.24)$ & [5.46-6.02/5.27-5.84] & 3.17 & 0.08 \\
\hline Competence ES & $0.76 / 0.78$ & $5.86(1.06)$ & $5.89(1.03)$ & [5.64-6.07/5.68-6.10] & .10 & 0.75 \\
\hline Relatedness MS & $0.95 / 0.95$ & $4.84(1.76)$ & $5.39(1.47)$ & [4.44-5.24/5.05-5.73] & 9.88 & $0.002^{* *}$ \\
\hline Relatedness ES & $0.91 / 0.91$ & $5.39(1.50)$ & $5.35(1.51)$ & [5.09-5.70/5.04-5.66] & 0.14 & 0.71 \\
\hline
\end{tabular}

MS = Middle School; ES = Elementary School; +alpha was 0.65 (pre) and 0.65 (post) so we removed "In this PE class, I have to force myself to do the activities".

Table 4

Students' self-determined motivation in middle and elementary school TGM lessons

\begin{tabular}{|c|c|c|c|c|c|c|}
\hline $\begin{array}{c}\text { Self-determined } \\
\text { motivation }\end{array}$ & $\begin{array}{c}\text { Alpha } \\
\text { (pre/post) }\end{array}$ & $\begin{array}{c}\text { Pre } \\
M( \pm S D)\end{array}$ & $\begin{array}{c}\text { Post } \\
M( \pm S D)\end{array}$ & 95\% CI [pre/post] & $\mathrm{F}$ & $p$ \\
\hline Intrinsic MS & $0.90 / 0.93$ & $5.73(1.32)$ & $5.65(1.32)$ & [5.42-6.03/5.35-5.95] & 0.29 & 0.59 \\
\hline Intrinsic ES & $0.87 / 0.89$ & $5.96(1.43)$ & $5.70(1.58)$ & [5.67-6.26/5.38-6.02] & 6.29 & $0.01^{*}$ \\
\hline Identified MS & $0.77 / 0 / 88$ & $5.37(1.31)$ & $5.47(1.30)$ & [5.07-5.67/5.18-5.77] & 0.53 & 0.47 \\
\hline Identified ES & $0.83 / 0.84$ & $5.89(1.30)$ & $5.74(1.37)$ & [5.62-6.16/5.46-6.02] & 1.68 & 0.20 \\
\hline Introjected MS & $0.75 / 0.75$ & $4.13(1.59)$ & $4.58(1.54)$ & [3.77-4.50/4.23-4.94] & 5.58 & $0.02^{*}$ \\
\hline Introjected ES & $0.64 / 0.66+$ & $4.35(1.56)$ & $4.32(1.59)$ & [4.03-4.67/3.99-4.64] & 0.07 & 0.79 \\
\hline External MS & $0.87 / 0.92$ & $3.49(1.71)$ & $4.07(1.91)$ & [3.10-3.88/3.63-4.50] & 9.06 & 0.004 \\
\hline External ES & $0.80 / 0.83$ & $4.18(1.81)$ & $4.18(1.80)$ & [3.81-4.55/3.80-4.55] & 0.001 & 0.98 \\
\hline Amotivation MS & $0.90 / 0.90$ & $2.41(1.60)$ & $3.46(1.97)$ & [2.05-2.78/3.01-3.91] & 20.89 & $0.000^{* * *}$ \\
\hline Amotivation ES & $0.80 / 0.87$ & $2.28(1.59)$ & $2.25(1.62)$ & [1.96-2.61/ 1.91-2.58] & 0.07 & 0.80 \\
\hline
\end{tabular}

+ Reference needed to support this being below target value. 
Main effects of MANOVA for the selfdetermined motivation scales also revealed significant main effects in SDT constructs for the middle school (Wilks' Lambda $=.77, F(5,71)=$ 4.36, $\left.p=.002, \eta p^{2}=.24\right)$, but not the elementary school (Wilks' Lambda $=.93, F(5,88)=1.44, p=$ $\left..21, \eta_{p}^{2}=.08\right)$. Follow-up univariate ANOVAs for the middle school group revealed that there was a significant increase in introjected regulation $(F(1$, $\left.75)=5.58, p=.02, \eta p^{2}=.07\right)$, external regulation $\left(F(1,75)=9.06, p=.004, \eta p^{2}=.11\right)$, and amotivation $\left(F(1,75)=20.89, p=.000, \eta_{p^{2}}=.22\right)$ (Table 4).

\section{Lesson Context and Teacher Behavior}

At the middle school, approximately $48 \%$ of lesson time was game play, $22 \%$ skill practice, with the remaining time comprised of approximately $17 \%$ management, and $13 \%$ knowledge (see Table 1 for specific mean and standard deviations). At the elementary school, slightly less lesson time (42\%) was spent in game play, with $22 \%$ skill practice, approximately $17 \%$ management, and 19\% knowledge (Table 1).

The middle school teacher primarily used verbal instruction, followed by management, corrective feedback, specific observation, modeling and general observation (Table 2). Positive feedback was low at under $5 \%$ of the total behaviors utilized. A similar behavioral profile for teacher behavior to the middle school teacher was noted for the elementary teacher who also primarily used instruction, followed by management, specific observation, corrective feedback, modeling and general observation (Table 2). Once again, positive feedback was low, at approximately only $3 \%$ of total behaviors utilized.

\section{Discussion}

The purpose of this study was to investigate potential changes in middle and elementary school students' perceptions of need satisfaction and self-determined motivation over the duration of a TGM-focused basketball unit. It was hypothesized that students would increase their perceptions of need satisfaction and the quality of their motivation due to their experiences participating in TGM-focused lessons. The research was carried out in a context where the teachers and students had no previous experience of the TGM, although the middle school teacher had previous experience of teaching using the Sport Education Model, which employs cooperative and constructivist pedagogy. Results showed that the middle school teacher significantly increased his students' perceptions of relatedness over the duration of the study. The increase in the perception of relatedness observed as a result of the teacher employing the TGM had been reported in previous studies (Mandigo et al., 2008). This result is not surprising given that the lesson context data demonstrated that students spent $70 \%$ of the lesson in skill practice or game play and less time in the knowledge lesson context than the elementary teacher (Table 1). Moreover, the teacher behavior data indicated that the teacher spent a significant amount of time interacting with students through verbal instruction during skill practice or game play (which included questioning). This may have been a result of his previous experience using the Sport Education Model, which like the learning environment for the TGM, necessitates students work in small groups (i.e. in the current study middle school students worked in small groups of six at one basket) and the teacher steps back to specifically observe students in skill practice and game play with the aim of providing them with individual and small group instruction/feedback.

These results were not mirrored at the elementary school where, in contrast to the middle school teacher, the elementary teacher's students' perceptions of autonomy were significantly reduced over the duration of the study. These results are not consistent with previous research on sport-focused constructivist teaching models (Mandigo et al., 2008; Wallhead et al., 2014), but are consistent with other studies in physical education that recognize the positive and significant effect of the teacher's behavior on students' perceptions of autonomy (De Meyer et al., 2014; Standage et al., 2005; Taylor and Ntoumanis, 2007). Our results, in part, may be a reflection of the teacher behavior/lesson context results and the wider context in which the study was conducted. For example, instruction, modeling and corrective feedback were all highly utilized teaching behaviors by the elementary teacher, and lesson context results revealed higher levels of whole group instruction - verified by the time spent in the knowledge lesson context - than at the middle school (Table 1). The main whole group instruction observed was the teacher 
setting up the skill practices where s/he was the main protagonist in modelling the tactical/technical skills s/he expected the students to replicate. There was, therefore, little room for student expression, creativity and choice.

In terms of the wider study context, data collection at the elementary school took approximately ten weeks to complete because the students only had physical education class once per week. Moreover, the time to complete the study data collection became extended when lessons were missed due to snow days, meaning students missed their one lesson of physical education that week. This factor, and that fact that these students were previously used to the units of even shorter duration than the current unit in a multi-activity type of curriculum, may have legitimate reasons for decreases in their perceptions of autonomy. Results may have been different if changes over multiple units of the TGM had been examined.

Given the significant increases we observed in relatedness in the middle school, it was surprising to find significant increases in students' perceptions in three self-determined motivation variables: introjected regulation, external regulation and amotivation. However, it can be argued that although results showed a high level of interactions between the teacher and individual/small groups of students, which can result in more immediate changes in students' perceptions of relatedness, the fact that the teacher still utilized high levels of verbal instruction and gave mainly corrective feedback, may have meant that the students remained focused on extrinsically pleasing the teacher. Moreover, the fact that students played games in mixed-gender groups, which were small in size, may have meant that students were more likely to compare themselves to others, particularly when being provided with specific individual verbal instruction and/or feedback as being specifically observed by the teacher. The middle school teacher may need to utilize different ways of providing individual feedback, particularly if corrective (i.e., pulling students out one-on-one away from other students to question or provide feedback), to ensure that students feel more autonomous in their motivation. In addition, alternating the groups and providing choices for the students in which groups they wanted to participate in may have reduced feelings of controlled motivation. While the middle school teacher did, in some lessons, allow students to move baskets to play different teams, they stayed in the same persistent team for the duration of the unit. While the use of persistent teams has been shown to be beneficial in the Sport Education Model, the lack of roles, student rather than teacher-led discussions, and opportunities for students rather than the teacher(s) to plan/change/modify conditions of the game (e.g. by allowing each student only three dribbles to reduce one player dominating the game) in the current study may have increased students' sense of autonomous rather than controlled motivation (Hastie et al., 2014; Perlman, 2010; Rutten et al., 2012; Wallhead et al., 2013). Moreover, these results may have been different if we had studied the changes over multiple units of the TGM within the current context because this was the students' first exposure to the TGM, and research shows that students can initially be resistant to their teacher using new pedagogical models such as the TGM (Gurvitch et al., 2008).

In terms of the elementary school, no significant overall multivariate main effect for self-determined motivation was noted. Having said that, while it is positive that students did not feel more controlled motivation like in the middle school group, the lack of significant changes to perceptions of autonomous motivation may have been due to similar reasons highlighted above for the middle school teacher (i.e., lack of student-led group discussions, students were not given opportunities to change/modify rules to meet their groups'/teams' own needs, the lack of 'roles', the teacher providing feedback individually but in front of other students, teachers demonstrating games and skills drills rather than students, etc.).

While these aforementioned behaviors and lesson structures have been listed as synonymous with the TGM, the teachers in this study were still very new to the TGM. Although they worked well enough to satisfy TGM benchmarks, they remained very directive in their utilization of the TGM (Metzler, 2011) as can be seen from the high amounts of what could be perceived by students as controlling teacher behaviors such as verbal instruction, feedback (mainly corrective) and modeling (teachers demonstrating). It would have been interesting to 
see the teachers continue to utilize the TGM over a longer period of time as this may have increased students' familiarity with the model (Gurvitch et al., 2008). Moreover, this would provide the teachers with the opportunity to be able to integrate some of the alternative pedagogical strategies and skills suggested previously, and observe how these changes (i.e. using less controlling teaching behaviors) may have affected their students' motivation. For example, if the teachers had utilized strategies such as 'tactical timeouts' to stimulate within-team debate of ideas (Gréhaigne et al., 2005), then we would have expected to see more specific observation being recorded using the teacher behavior instrument as the teacher listened to groups' discussions, provided them with positive feedback, and prompted them with more questions (Harvey and Light, 2015). These types of behaviors have been shown to satisfy students' needs (Morgan et al., 2005) and encourage more autonomous (intrinsic) motivation (Reeve and Jang, 2006).

We can point to several strengths of the current study. First, we collected need satisfaction and motivation data from multiple classes before and after the TGM lessons were delivered. Second, the collection of lesson context and teacher behavior variables added much needed descriptive information to contextualize our findings. Third, not only were teachers trained in their use of the TGM before the study commenced, the use of the pre-post design enabled these teachers to be supported and provided with feedback from research staff throughout their delivery of the TGM lessons, albeit specific results and data were never shared with the two teachers during the implementation phase of the study.

This study had limitations that should be addressed in future research. First, while the sample size in the current study was an improvement on that seen in the previous GCA research on motivation (Morgan et al., 2005; Moy et al., 2015; Smith et al., 2015), further increases are required to be able to generalize the current findings. In this regard, it would be interesting to include participants from different geographical locations (e.g. metropolitan area, regional town and rural area) and with different socioeconomic status. This increase in sample size would also allow for the construction of a structural equation (or path) model to examine the direct and indirect effects of need satisfaction on student motivation, which was not possible in this study. Second, this study only measured students' perceptions of their self-determined motivation. In future studies researchers could examine how students' perceptions of motivational climate in TGM lessons (task or ego) might be associated with their self-determined motivation and how these variables are predictive of: (a) in-lesson Moderate to Vigorous Physical Activity (MVPA), (b) out-ofclass/leisure time physical activity, and (c) psychomotor outcomes and decision-making, which can be measured through game play performance instruments such as the Team Sport Assessment Procedure (Gréhaigne et al., 2005) or the Game Performance Assessment Instrument (Mitchell et al., 2013). Third, in this study, teacher behaviors were analyzed by external observers using a systematic observation system covering a range of behaviors (e.g. verbal instruction, modeling, general observation, etc.). In future research, it would be interesting to investigate teacher behaviors utilizing instruments specific to observing the controlling or autonomy supportive behaviors of the teacher (De Meyer et al., 2014). Moreover, to gain a greater understanding of the students' perception of the teaching behaviors used by the teacher (controlling or autonomy supportive) and how this contributes to the satisfaction of the students' basic psychological needs, post-lesson student interviews could be utilized and triangulated with teacher behavior data (Gray et al., 2009). Alternatively, teacher behaviors could be included as variables in the previously mentioned structural equation (or path) model. Integrating some of these suggestions in a future study would highlight the specific aspects of TGM lessons that contribute to a higher quality of motivation (i.e., autonomous) in such lessons. Fourth, researchers in the current study utilized a pre-post design. In addition to considering the predictive models already discussed, future research may consider utilizing experimental designs such as cross over or delayed multiple baseline designs to investigate differences between groups taught through direct 'technique-skill' focused instruction, compared to TGM-focused lessons (Ward et al., 2014). Furthermore, the utilization of more experienced TGM teachers and/or examining changes in 
motivation over a series of TGM-focused units of greater length than the 6-8 lessons investigated in this study would assist in examining changes in motivation over time (Harvey et al., 2016; Miller, 2015; Smith et al., 2015). Additionally, while we hope these two teachers would continue to utilize the TGM, we have no evidence that being involved in the current study impacted their longterm integration of the TGM.

\section{Conclusions}

GCAs such as the TGM allow students to learn the tactical aspects of the game first by playing a developmentally appropriate smallsided and/or modified/conditioned version of the game. In this sense, there is an effective integration of the techniques within contextualized situations, which leads to greater motivation and enjoyment of students because they practice a sport in similar conditions to the real sport. Despite this, and while teachers met Metzler's key benchmarks for model fidelity, the results obtained in our research, except for relatedness at the middle school, are not consistent with previous research already published. Therefore, we suggest that it is important in future research to pay greater attention to the contextual factors associated with the application of the TGM, such as students' previous exposure to TGM lessons, and teachers' training and experience in utilizing the TGM. Indeed, results of the present study demonstrate that a longer-term commitment to the TGM is necessary to reduce controlling teacher behaviors, which will lead to positive changes in students' need satisfaction and self-determined motivation. Future research is therefore needed to embrace this challenge to provide an increased evidencebase for GCAs such as the TGM.

\section{References}

Bunker D, Thorpe R. A model for the teaching of games in secondary schools. Bulletin of Physical Education, 1982; 18: 5-8

De Meyer J, Tallir IB, Soenens B, Vansteenkiste M, Aelterman N, Van den Berghe L, Speleers L, Haerens L. Does observed controlling teaching behavior relate to students' motivation in physical education? J Educ Psychol, 2014; 106(2): 541-54

Deci EL, Ryan RM. The "what" and "why" of goal pursuits: Human needs and the self-determination of behavior. Psychol Inq, 2000; 11(4): 227-68

Ennis C. Creating and culturally relevant curriculum for disengaged girls. Sport Educ Soc; 4(1), 31-49

Gillet N, Vallerand RJ, Lafrenière MAK. Intrinsic and extrinsic school motivation as a function of age: The mediating role of autonomy support. Soc Psychol Educ, 2012; 15: 77-95

Goudas M, Biddle S, Fox K, Underwood M. 'It ain't what you do, it's the way that you do it!' Teaching style affects children's motivation in track and field lessons. Sport Psychol, 1995; 9(3): 254-64

Gray S, Sproule J, Morgan K. Teaching team invasion games and motivational climate. Eur Phys Educ Rev, 2009, 15(1): 65-89

Gréhaigne JF, Wallian N, Godbout P. Tactical-decision learning model and students' practices. Phys Educ Sport Pedagog, 2005; 10(3): 255-69

Griffin L. Improving net/wall game performance. J Phys Educ, Recr Dance, 1996; 67(2): 34-37

Gurvitch R, Blankenship B, Metzler M, Lund J. Student teachers' implementation of model-based instruction: Facilitators and inhibitors. J Teach Phys Educ, 2008; 27(4): 466-86

Harvey S, Cushion CJ, Sammon P. Dilemmas faced by pre-service teachers when learning about and implementing a game-centred approach. Eur Phys Educ Rev, 2015; 21(2): 238-56

Harvey S, Jarrett K. A review of the game-centred approaches to teaching and coaching literature since 2006. Phys Educ Sport Pedagog, 2014; 19(3): 278-300

Harvey S, Light RL. Questioning for learning in game-based approaches to teaching and coaching. Asia- 
Pacific Journal of Health, Sport and Physical Education, 2015; 6(2): 175-90

Harvey S, Song Y, Baek J, van der Mars H. Two sides of the same coin: Student physical activity levels during a game-centred soccer unit. Eur Phys Educ Rev, 2016; 22(4): 411-29

Hair JF, Anderson RE, Tatham RL, Black WC. Multivariate data Analysis (5th ed.). New York: Macmillan Publishing Company; 1998

Hastie PA, Casey A. Fidelity in models-based practice research in sport Pedagogy: A guide for future investigations. J Teach Phys Educ, 2014; 33(3): 422-31

Hastie P, Sinelnikov O, Wallhead T, Layne T. Perceived and actual motivational climate of a masteryinvolving sport education season. Eur Phys Educ Rev, 2014; 20(2): 215-28

Hawkins A, Wiegand R. West Virginia University teaching evaluation system and feedback taxonomy. In P Darst R Zakrajsek, V Mancini (Eds.), Analyzing Physical Education and Sport Instruction. Champaign, IL: Human Kinetics, 277-93, 1989

Jones RJA. Marshall S, Peters DM. Can we play a game now? The intrinsic value of TGfU. European Journal of Physical and Health Education, 2010; 4(2): 57-63

Kirk D. Physical education futures. London and New York: Routledge, 2010

Kirk D, Macdonald D. Situated learning in physical education. J Teach Phys Educ, 1988; 17(3): 376-87

Light R, Fawns R. Knowing the game: Integrating speech and action in games teaching through TGfU. Quest, 2003; 55(2): 161-76

Light RL, Harvey S, Mouchet A. Improving "at-action" decision-making in team sports through a holistic coaching approach. Sport Educ Soc, 2012; 19(3): 258-75

Light R, Kentel JA. Soft pedagogy for a hard sport? Disrupting hegemonic masculinity in high school rugby through feminist-informed pedagogy. In MD Kehler M Atkinson (Eds.), Boys' bodies: Speaking the unspoken. New York: Peter Lang Publishing; 133-52; 2010

Lonsdale C, Sabiston CM, Raedeke TD, Ha ASC, Sum RKW. Self-determined motivation and students' physical activity during structured physical education lessons and free choice periods. Prev Med, 2009; 48(1): 69-73

Mandigo J, Holt N, Anderson A, Sheppard J. Children's motivational experiences following autonomysupportive games lessons. Eur Phys Educ Rev, 2008; 14(3): 407-25

McKenzie T. SOFIT. System for Observing Fitness Instruction Time. Overview and training manual. San Diego, CA: San Diego State University; 2012

McLachlan S, Hagger MS. Effects of an autonomy-supportive intervention on tutor behaviors in a higher education context. Teach Teach Educ, 2010; 26(5): 1204-10

Metzler M. Instructional models for physical education (3rd ed.). Scottsdale, AZ: Holcomb Hathaway; 2011

Miller A. Games centered approaches in teaching children \& adolescents: Systematic review of associated student outcomes. J Teach Phys Educ, 2015; 34(1): 36-58

Mitchell S, Oslin J, Griffin L. Teaching sport concepts and skills: A tactical games approach (2nd ed.). Champaign, IL: Human Kinetics; 2006

Morgan K, Kingston K, Sproule J. Effects of different teaching styles on the teacher behaviours that influence motivational climate and pupils' motivation in physical education. Eur Phys Educ Rev, 2005; 11(3): 25785

Moy B, Renshaw I, Davids K. The impact of nonlinear pedagogy on physical education teacher education students' intrinsic motivation. Phys Educ Sport Pedagog, 2015; doi:10.1080/17408989.2015.1072506

Ntoumanis N, Standage M. Motivation in physical education classes: A self-determination theory perspective. Theory Res Educ, 2009; 7: 194-202

Nunnally JC, Bernstein IH. Psychometric theory (3rd ed.). New York: McGraw Hill Higher Education, 1994

Osborne J. Best practices in quantitative methods. Thousand Oaks, CA: Sage Publications; 2007 
Oslin J, Mitchell S. Game-centered approaches to teaching physical education. In D Kirk, D MacDonald, M O'Sullivan (Eds.), Handbook of physical education. London: Sage, 672-651; 2006

Perlman D. Change in affect and needs satisfaction for Amotivated students within the sport education model. J Teach Phys Educ, 2010; 29(4): 433-45

Perlman D. The influence of the Sport Education Model on amotivated students' in-class physical activity. Eur Phys Educ Rev, 2012; 18(3): 335-45

Potrac P, Jones R, Armour K. 'It's all about getting respect': The coaching behaviours of an expert English soccer coach. Sport Educ Soc, 2002: 7(2): 183-202

Reeve J, Jang H. What teachers say and do to support students' autonomy during a learning activity. J Educ Psychol, 2006; 98(1): 209-218

Rutten C, Boen F, Seghers J. How school social and physical environments relate to autonomous motivation in physical education: The mediating role of need satisfaction. J Teach Phys Educ, 2012; 31(3): 216-30

Ryan RM, Deci EL. Self-determination theory and the facilitation of intrinsic motivation, social development, and well-being. Am Psychol, 2000; 55(1): 68-78

Smith L, Harvey S, Savory L, Fairclough S, Kozub S, Kerr C. Physical activity levels and motivational responses of boys and girls: A comparison of direct instruction and tactical games models of games teaching in physical education. Eur Phys Educ Rev, 2015; 21(1): 93-113

Standage M, Duda JL, Ntoumanis N. A test of self-determination theory in school physical education. Brit J Educ Psychol, 2005; 75(3): 411-33

Stolz S, Pill S. Teaching games and sport for understanding: Exploring and reconsidering its relevance in physical education. Eur Phys Educ Rev, 2014; 20(1): 36-71

Tabachnick BG, Fidell LS. Using multivariate statistics (6th ed.). Boston: Pearson; 2014

Taylor IM, Ntoumanis N. Teacher motivational strategies and student self-determination in physical education. J Educ Psychol, 2007; 99(4): 747-60

Wallhead TL, Garn AC, Vidoni C. Sport education and social goals in physical education: Relationships with enjoyment, relatedness, and leisure-time physical activity. Phys Educ Sport Pedagog, 2013; 18(4): 427-41

Wallhead TL, Garn AC, Vidoni C. Effect of a sport education program on motivation for physical education and leisure-time physical activity. Res Q Exercise Sport, 2014; 85(4): 478-87

Wallhead TL, Hagger M, Smith DT. Sport Education and Extracurricular Sport Participation. Res $Q$ Exercise Sport, 2010; 81(4): 442-55

Wallhead TL, Ntoumanis N. Effects of a sport education intervention on students' Motivational responses in physical education. J Teach Phys Educ, 2004; 23(1): 4-18

Ward P, Kim I, Ko B, Li W. Effects of improving teachers' content knowledge on teaching and student learning in physical education. Res Q Exercise Sport, 2014; 86(2): 130-39

Werner P, Thorpe R, Bunker D. Teaching Games for Understanding: Evolution of a Model. J Phys Educ, Recr Dance, 1996; 67(1): 28-33

\section{Corresponding author: \\ Stephen Harvey}

Associate Professor, Patton College of Education,

Department of Recreation and Sport Pedagogy,

Room 202N, McCracken Hall, Ohio University, Athens, OH, 45701.

E-mail: harveys3@ohio.edu 